\title{
A generation effect with numbers rather than words
}

\author{
JOHN M. GARDINER and JEAN M. C. ROWLEY \\ The City University, London, England
}

\begin{abstract}
It has previously been shown that a word from a list is more likely to be remembered if the word was generated, rather than read, by the subject. Two simple experiments that show that a similar generation effect occurs in remembering answers to multiplication sums are described. It is suggested that this finding is inconsistent with a strong version of a lexical activation hypothesis that had been proposed to account for the generation effect. According to that hypothesis, the generation effect is due to enhanced activation of the semantic features of a word's representation in the subjective lexicon.
\end{abstract}

In a series of recent studies, Slamecka and his colleagues have shown that a word from a list is more likely to be remembered if it is generated, rather than read, by the subject (McElroy \& Slamecka, 1982; Slamecka \& Fevreiski, 1983; Slamecka \& Graf, 1978; see, too, Jacoby, 1978, 1983). This phenomenon-the generation effect-has been found to occur in both recall and recognition memory tests, and to be quite uninfluenced by the rule or context provided for generate and read tasks (Slamecka \& Graf, 1978; see, too, Gardiner \& Arthurs, 1982). It has also been found, however, that the type of item generated is critical, for the effect has been shown not to occur with nonwords (McElroy \& Slamecka, 1982). This finding led McElroy and Slamecka to infer that involvement of semantic memory is a necessary condition for the generation effect, and to propose the more specific hypothesis that the effect is due to enhanced activation of semantic features of a word's representation in the subjective lexicon. As Slamecka and Fevreiski (1983) put it, "generation will have functional consequences only if the generated unit already has representation in the subjective lexicon. That is, the generational product must be a word in one's vocabulary, and therefore must possess semantic attributes"' (p. 161).

This interpretation gained additional support from the results of Slamecka and Fevreiski's (1983) study, which showed that subjects' attempts to generate the required words need not be successful for a generation effect to occur (see, too, Gardiner, Craik, \& Bleasdale, 1973), and also from Jacoby's (1983) elegant demonstration that, although generated words were better remembered in a

We thank James A. Hampton for helpful suggestions. A preliminary report of these experiments was included in a paper given by John $\mathbf{M}$. Gardiner and James A. Hampton at the London Conference of the British Psychological Society, December 1983. The authors' mailing address is: Division of Psychology, The City University, Northampton Square, London EC1V 4PB, England. test of recognition memory, in a visual-perception identification task it was the read words that were more likely to be identified. Thus, generating the surface features of the required word was not critical, and, for an identification task in which surface features were at a premium, reading was actually more advantageous than generating. It seems clear, therefore, that the semantic features of a word, as opposed to its surface features, give rise to the generation effect.

The lexical activation hypothesis proposed by $\mathrm{McEl}$ roy and Slamecka (1982) strongly suggests a need for further evidence on the generality of the effect with respect to the type of item used; the question of whether there are kinds of item other than words that might produce an effect has an obvious bearing on the hypothesis. For example, the hypothesis would be further confirmed were it to be shown that no generation effect occurs when numerical items are used in the context of some arithmetic operation, such as multiplication. On the other hand, were it to be shown that such numbers do give rise to a generation effect, then the lexical activation hypothesis would be rejected-at least as presently formulated. (It would, of course, be possible to fall back on some weaker version of the hypothesis, and reject only the strong version.) There appears to be little evidence available on the question of whether or not a generation effect does occur with numerical items; hence, we describe two simple experiments that were designed to provide such evidence. ${ }^{1}$

\section{EXPERIMENT 1}

In Experiment 1, the subjects studied a list that consisted of familiar multiplication sums. Half of the sums were presented in a generate task, that is, without the answers, and half were presented in a read task, that is, with the answers. Afterwards, the subjects were given a recognition memory test for the answers to all the sums from the list. 


\section{Method}

Design. The design had one within-subjects variable: task (generate vs. read). All subjects studied a single list of 20 multiplication sums; 10 of the answers were generated, and 10 were read. They were then given two successive recognition tests in which they had to identify those answers from among other, lure answers to similar multiplication sums. The first test was a free-choice test in which they were instructed not to guess; the second was a forced-choice test.

Materials. From the 2-times multiplication table up to the 12-times multiplication table there are 40 two-digit answers, excluding 10 and 12. These 40 numbers were divided arbitrarily into two equal sets, one for use in the study list and one for use in the recognition test as lures. For any subset of answers all beginning with the same digit, list items and lures were divided as evenly as possible. For example, of the 7 answers that fall within the 20 to 29 range, 4 served as target responses and 3 as lures. Multiplication surns were then chosen for each target response in such a way that nine of the multiplication tables were used twice and two once.

Procedure. The list items were presented as numbers on cards at the rate of $4 \mathrm{sec}$ each. For 10 of the items, the answer to the sum was shown, and for the other 10, a question mark was shown instead (e.g., $9 \times$ $4=36 ; 8 \times 5=$ ?). Generate items for half the subjects were read items for the other half, and the task was blocked such that half the subjects began with generate items and half with read items. Within each block, the sums were randomly reordered for each subject. The subjects had to say aloud both the sum and its answer in both generate and read conditions. They were told that subsequently their memory for the answers to those particular sums would be tested. In order to reduce performance levels somewhat, a free-association test was interpolated between the study list and the recognition tests. In this test, the experimenter read out a series of 30 stimulus words, 1 word at a time, and the subjects had to respond rapidly by saying aloud the first word they thought of in connection with each stimulus. The recognition tests were then administered. They were presented on a single sheet on which the 20 target numbers and the 20 lure numbers were randomly mixed together. In the first test, the subjects were instructed to work carefully down each column without backtracking and to circle any numbers that they felt sure were answers to the sums they had called out earlier. After completing this test, they were told that, in fact, 20 of the 40 numbers on the sheet were answers to those sums and that, using a pen of a different color, they were to continue selecting targets until they had selected up to a total of 20 , if necessary making just the best guesses they could.

Subjects. The subjects were 24 undergraduate students at The City University, London, who volunteered to participate in the experiment without pay. They were tested individually. Two subjects unaccountably experienced some difficulty with the generation task and were replaced.

\section{Results and Discussion}

The probability of a false-positive response in the initial, free-choice test was .07 . Recognition probabilities for each recognition test are shown in Figure 1, from which it is obvious that there is superior recognition following the generate task. The results of two separate ANOVAs carried out on the number of words correctly recognized by each subject showed that the generation effect was highly significant in both the free-choice test $[F(1,23)=49.09$, MSe $=2.22, \mathrm{p}<.001]$ and the forced-choice test $[\mathrm{F}(1,23)=35.56, \mathrm{MSe}=1.35, \mathrm{p}<$ $.001]$. Thus, at least so far as recognition memory is concerned, there is a generation effect with these numbers comparable to that previously obtained with words.

\section{EXPERIMENT 2}

In Experiment 2, the subjects studied the same list of multiplication sums, and again, half of the sums were

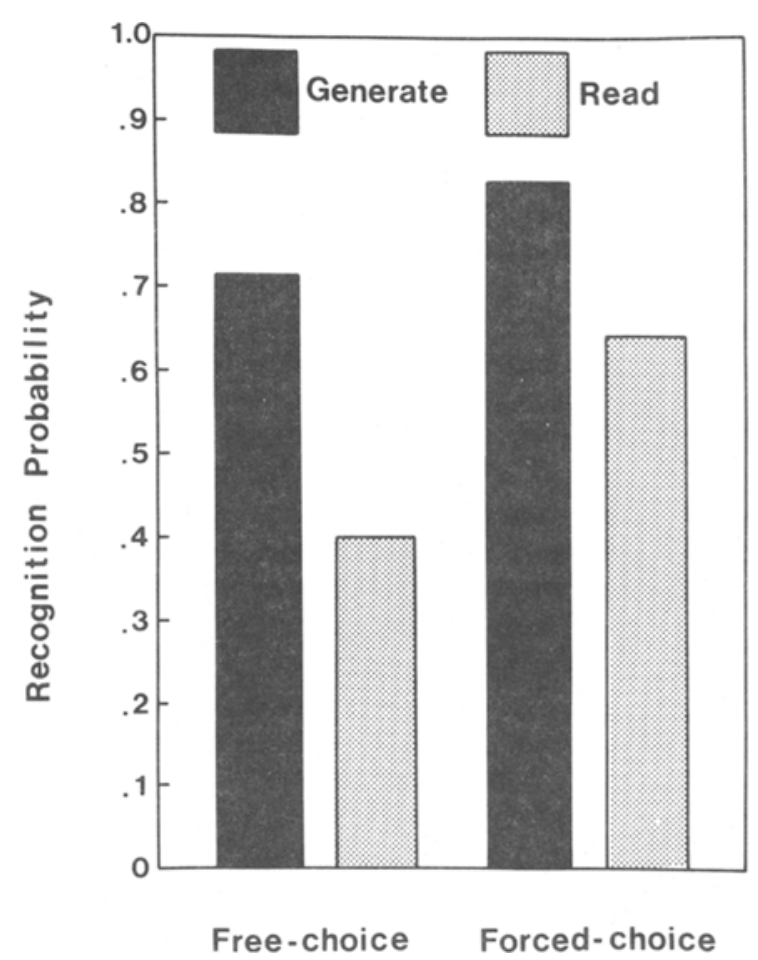

Figure 1. Mean recognition probabilities in Experiment 1.

presented in a generate task and half in a read task. Experiment 2, however, involved multitrial free-recall learning, for it was designed to investigate the possibility that, unlike the generation effect with words, a generation effect with numbers might occur only in recognition memory.

\section{Method}

Design and Procedure. The design was a $2 \times 3$ factorial with task (generate vs. read) and trials (1-3) both as within-subjects factors. Apart from the use of free-recall leaming, in most other respects Experiment 2 was essentially identical to Experiment 1, for the list items and their manner and rate of presentation were the same. The ordering of items within each generate and read block was varied across trials. A different free-association test, reduced from 30 to 20 stimulus.words, was given immediately after each study trial and before recall. The recall tests were written and terminated by the subjects. The next study trial then began immediately. On a very few occasions on the first trial, a subject failed to generate the answer to the sum within $4 \mathrm{sec}$; when that happened, the answer was given before the next sum was presented.

Subjects. The subjects were 24 students at The City University, London, who volunteered to participate in the experiment without pay. They were tested individually.

\section{Results and Discussion}

The recall probabilities are shown in Figure 2, from which it can be seen that recall is markedly superior following the generate task. The results of an ANOVA carried out on the number of words recalled by each subject revealed a highly significant generation effect $[F(1,23)$ $=36.78, \mathrm{MSe}=3.29, \mathrm{p}<.001]$, as well as a highly significant effect of trials $[\mathrm{F}(2,46)=90.48, \mathrm{MSe}=0.66$, $\mathrm{p}<.001]$. The interaction was not significant $[F(2,46)$ 


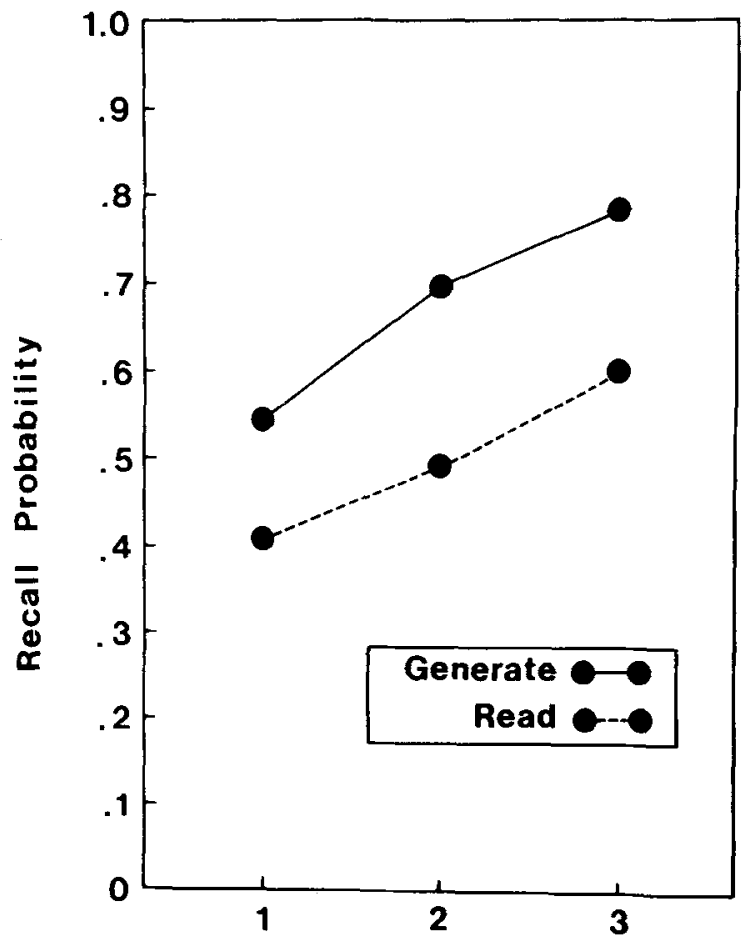

Trial

Figure 2. Mean free-recall probabilities in Experiment 2.

$=2.61, \mathrm{MSe}=0.87]$. The results of this experiment therefore show that a generation effect with numbers may be obtained as readily with multitrial free-recall learning as with recognition memory testing.

\section{CONCLUSIONS}

The results of this study demonstrate that a similar generation effect occurs in remembering numbers from multiplication tables to that found previously in remembering words from a word list. This outcome seems inconsistent with the lexical activation hypothesis proposed by McElroy and Slamecka (1982). According to that hypothesis, the generation effect is due to enhanced activation of the semantic features of a word's representation in the subjective lexicon.

Of course, although largely devoid of semantic attributes, numbers will undoubtedly be assumed to be represented in the subjective lexicon by many theorists, and so it remains quite possible to retain some weaker version of the lexical activation hypothesis, despite the existence of a generation effect with numbers. However, the lexical activation hypothesis was, in our view, prematurely specific, and we prefer to argue for a broader view. Although agreeing with McElroy and Slamecka (1982) that semantic memory involvement seems to be a necessary condition for the generation effect, we suggest in contrast that any type of item at all may give rise to a generation effect, provided only that it activates some existing representation in some knowledge system in semantic memory. Perhaps the point is more aptly expressed in a caveat by Kintsch (1980), who warned that "attempts to equate semantic mernory with word meanings only, that is, with the 'subjective lexicon,' are misguided and doomed to failure. Semantic memory is our whole-world knowledge-including what we know about robins, $7 \times$ $4=28$, what to do in a restaurant, and the history of the Civil War, to cite some prominent examples", (p. 596).

\section{REFERENCES}

Gardiner, J. M., \& ArThurs, F. S. (1982). Encoding context and the generation effect in multitrial free-recalling learning. Canadian Joumal of Psychology, 36, 527-531.

Gardiner, J. M., Craik, F. I. M., \& Bleasdale, F. A. (1973), Retrieval difficulty and subsequent recall. Memory \& Cognition, 1, 213-216.

JACOBY, L. L. (1978). On interpreting the effects of repetition: Solving a problem versus remembering a solution. Journal of Verbal Leaming and Verbal Behavior, 17, 649-667.

JACOBY, L. L. (1983). Remembering the data: Analyzing interactive processes in reading. Journal of Verbal Leaming and Verbal Behavior, 22, 485-508.

KINTSCH, W. (1980). Semantic memory: A tutorial. In R. S. Nickerson (Ed.), Attention and performance VIII. Hillsdale, NJ: Erlbaum.

McElroy, L. A., \& Slamecka, N. J. (1982). Memorial consequences of generating nonwords: Implications for semantic-memory interpretations of the generation effect. Journal of Verbal Learning and Verbal Behavior, 21, 249-259.

Russo, J. E., \& WISHER, R. A. (1976). Reprocessing as a recognition cue. Memory \& Cognition, 4, 683-689.

SlamecKa, N. J., FeVReIsKI, J. (1983). The generation effect when generation fails. Journal of Verbal Leaming and Verbal Behavior, 22, 153-163.

SLAMECKA, N. J., \& GRAF, P. (1978). The generation effect: Delineation of a phenomenon. Journal of Experimental Psychology: Human Learning and Memory, 4, 592-604.

\section{NOTE}

1. There is some evidence indicating superior recognition of internally generated numbers (e.g., Russo \& Wisher, 1976).

(Manuscript received March 15, 1984; revision accepted for publication May 24, 1984.) 